\title{
Effect of Static Magnetic Field on Nucleation of Cobalt Nitrate Hexahydrate
}

\author{
Annisa Rahman , Akhmad Yusuf", Risky Afandi Putria, Yunita Anggraini ${ }^{a}$, Febri Berthalita \\ Pujaningsih $^{b}$, Daniel Kurnia ${ }^{a}$, Surjamanto Wonorahardjo ${ }^{c}$ (D), Inge Magdalena Sutjahja ${ }^{a}$ (D) \\ anstitut Teknologi Bandung, Faculty of Mathematics and Natural Sciences, Department of Physics, \\ Bandung 40132, Indonesia. \\ ${ }^{b}$ Universitas Jambi, Faculty of Education and Teacher Training, Department of Physics Education, \\ Jambi 36361, Indonesia. \\ 'Institut Teknologi Bandung, School of Architecture, Planning, and Policy Development, Department of \\ Architecture, Bandung 40132, Indonesia.
}

Received: February 16, 2021; Revised: June 26, 2021; Accepted: August 12, 2021

\begin{abstract}
Freezing of cobalt nitrate hexahydrate $(\mathrm{CoNHH})$ under a static magnetic field was studied at three different magnetic field intensities. The results show that the magnetic field has a significant effect when the sample enters the solid phase and reduces the stochastic behaviour of the nucleation. Thermal properties investigated using thermogravimetric and differential thermal analysis revealed the shift to a lower temperature for the onset of decomposition and melting temperature after the freeze-thaw in a magnetic field. Besides that, we observed a significant change in the FT-IR peaks that might indicate the emergence of cobalt nitrate with a lower hydrate number, a phase separation effect, and the evaporation of $\mathrm{NO}_{3}^{-}$ions. Refinement of the XRD spectra shows a single phase of CoNHH with a slight lattice parameter change after the freezing-thawing in a magnetic field. The freezing behaviour of CoNHH was compared to that observed previously for water, a salt solution, and an ethylene glycol solution. We investigated the relationship of the freezing behaviour with hydrogen bonding and magnetic properties and its impact on the change in the Gibbs free energy. The results of this study are important to optimise the performance of $\mathrm{CoNHH}$ as latent thermal energy storage.
\end{abstract}

Keywords: Cobalt Nitrate Hexahydrate $\mathrm{Co}\left(\mathrm{NO}_{3}\right)_{2} \cdot 6 \mathrm{H}_{2} \mathrm{O}$, Nucleation, Supercooling Degree, Static Magnetic Field.

\section{Introduction}

The diminishing availability of fossil resources, in addition to negative impacts on the environment, has accelerated the shift towards sustainable energy resources ${ }^{1}$. The utilisation of natural resources such as solar radiation, ocean waves, wind, and biogas has contributed significantly to the process of restoring natural balance while also fulfilling the demand for energy. However, due to the energy crisis, an optimal method to store renewable energy is crucial. These circumstances encourage the development of a method to ensure efficient and sustainable energy storage ${ }^{1}$.

Energy storage plays an important role in energy conservation and utilisation of renewable energy. One of the technologies for storing energy that has undergone rapid development in the last 20 years is thermal energy storage (TES). TES stores thermal energy in the form of latent or sensible heat through heating (melting, evaporation) or cooling (freezing, condensation) of the storage medium. The stored energy will be ready for utilisation later when the process is reversed. TES technology, which has developed since 1970s, can be one of the solutions for overcoming the imbalance between energy supply and demand and can

*e-mail: inge@fi.itb.ac.id make significant contributions to meet the need for energy in a more efficient and environmentally friendly manner ${ }^{2}$.

Latent TES using a phase change material (PCM) is considered more efficient than sensible TES because it offers greater energy density (per unit mass or volume), with a small temperature difference (even almost zero) between the charging and discharging processes ${ }^{3,4}$. Organic or inorganic PCMs, however, have their advantages and disadvantages ${ }^{5}$. In particular, a relatively high supercooling degree and phase separation effect are the main considerations for inorganic salt hydrate PCMs, besides the possibility of a change in the stoichiometric composition during heating and cooling ${ }^{6,7}$.

Several active methods have been used to reduce the supercooling degree of salt hydrate PCMs, including water and salt solutions, by applying an electric field, magnetic field, ultrasound, or high pressure (Refs.$^{8-10}$ ). To date, freezing under pulsed, static, or oscillating magnetic fields was limited to water, salt solution, or ethylene glycol $^{11-15}$, and several contradicting results have been obtained from the experimental reports, so its effectiveness is still under debate ${ }^{16}$. Meanwhile, many inventions have been patented ${ }^{16}$ and technologies have been developed with either purely magnetic effects or combinations of electric fields, and freezing has attracted attention for food and biological product storage ${ }^{14,16-19}$. 
The cells alive system $(\mathrm{CAS})^{20}$ and proton freezers ${ }^{21}$ are among the leading technological products that offer many advantages compared with the conventional freezing method. These technologies are promising because freezing under magnetic fields has resulted in smaller ice crystals and more homogeneously distribution, thus minimising the damage and maintaining the quality of the preserved samples ${ }^{16,20,21}$.

In this paper, we report an experimental study of the effect of a static magnetic field on the nucleation process of the salt hydrate cobalt nitrate hexahydrate $\left(\mathrm{Co}\left(\mathrm{NO}_{3}\right)_{2} \cdot 6 \mathrm{H}_{2} \mathrm{O}\right.$, referred to as $\mathrm{CoNHH}$ ). The molecular structure of $\mathrm{CoNHH}$ comprises $\mathrm{Co}^{2+}$ ions bonded with $\mathrm{NO}_{3}$ - ions, surrounded by six water molecules to form a hexagonal configuration ${ }^{22}$. The red crystal of $\mathrm{CoNHH}$ has a monoclinic structure with the space group $\mathrm{C} 2 / \mathrm{c}^{23}$.

The study was based on an analysis of the temperature-time graph during nucleation under the influence of a static magnetic field with three different intensities from a permanent magnet. The examination parameters consist of the temperature and time characteristics of nucleation and freezing, supercooling degree, and total crystallisation period. The thermophysical properties of $\mathrm{CoNHH}$ from previous studies related to its performance as latent TES are summarised in Table 1.

To date, not many studies have investigated this magnetic PCM, possibly due to the complex thermal properties $^{24,28,29}$ and the fact that it is even more expensive than other salt hydrate PCMs that are commonly based on alkaline or alkaline earth metals, such as $\mathrm{CaCl}_{2} \cdot 6 \mathrm{H}_{2} \mathrm{O}$.
A recent study based on differential scanning calorimetry (DSC) measurements by Honcová et al. ${ }^{24}$ showed that the supercooling degree of CoNHH is dependent sensitively on the freezing-thawing cycle, being $14^{\circ} \mathrm{C}$ for the first cycle and $25^{\circ} \mathrm{C}$ for the fourth cycle. Furthermore, an additional $1 \mathrm{mass} \%$ of $\mathrm{CaO}$ as a nucleating agent to $\mathrm{CoNHH}$ reduces the supercooling degree to $8.1^{\circ} \mathrm{C}$ and becomes higher for faster heating/cooling rates. The smallest supercooling degree of $(7.9 \pm 2.5){ }^{\circ} \mathrm{C}$ was obtained for 1 mass $\%$ of nucleating agent mixture with a ratio of $1: 1$, consisting of graphite and $\mathrm{Ba}(\mathrm{OH})_{2} \cdot 8 \mathrm{H}_{2} \mathrm{O}$ to $\mathrm{CoNHH}$. The results of this study aimed to study the magnetic field effect to nucleation of $\mathrm{CoNHH}$ and to optimize its performance as latent TES.

\section{Methods}

Sample CoNHH (molecular weight $291.04 \mathrm{~g} / \mathrm{mol}$ ) with a purity of $98 \%$ was purchased from Sigma Aldrich. Samples with a mass of $3 \mathrm{~g}$ were placed in a test tube with an outer diameter of $1.34 \mathrm{~cm}$ and length of $15 \mathrm{~cm}$. The temperature sensor is a T-type thermocouple with a diameter of approximately $1 \mathrm{~mm}$ and an accuracy of $0.2 \%+1{ }^{\circ} \mathrm{C}$. For data recording, eight channel thermocouples are connected to an Applent data logger ${ }^{30}$. The magnetic field intensity was measured using a digital magnetic meter (Mg 3002).

The experimental system for nucleation under a magnetic field is shown in Figure 1. An adiabatic bath

Table 1. Thermophysical properties of $\mathrm{CoNHH}$ from previous studies.

\begin{tabular}{ccccccc}
\hline$T_{m}\left({ }^{\circ} \mathrm{C}\right)$ & $\Delta \mathrm{T}_{s}\left({ }^{\circ} \mathrm{C}\right)$ & $\Delta \mathrm{H}_{\text {fus }}\left(\mathrm{J} \mathrm{g}^{-1}\right)$ & $c_{p, l}\left(\mathrm{~J} \mathrm{~g}^{-1} \mathrm{~K}^{-1}\right)$ & $c_{p, s}\left(\mathrm{~J} \mathrm{~g}^{-1} \mathrm{~K}^{-1}\right)$ & $\rho_{s}\left(\mathrm{~g} \mathrm{~mL}^{-1}\right)$ & Reference \\
\hline 56 & 14 & 140 & & 1.682 & $2.04 \pm 0.05$ & 24 \\
\hline $\left.46.9 \pm 1.76^{*}\right)$ & 13 & $131 \pm 15$ & $3.45 \pm 0.74$ & $2.22 \pm 0.05$ & - & 25 \\
\hline $\left.51.5 \pm 0.5^{*}\right)$ & - & - & - & - & - & 26 \\
\hline 57 & - & 128 & - & - & 27 \\
\hline
\end{tabular}

*) Freezing temperature

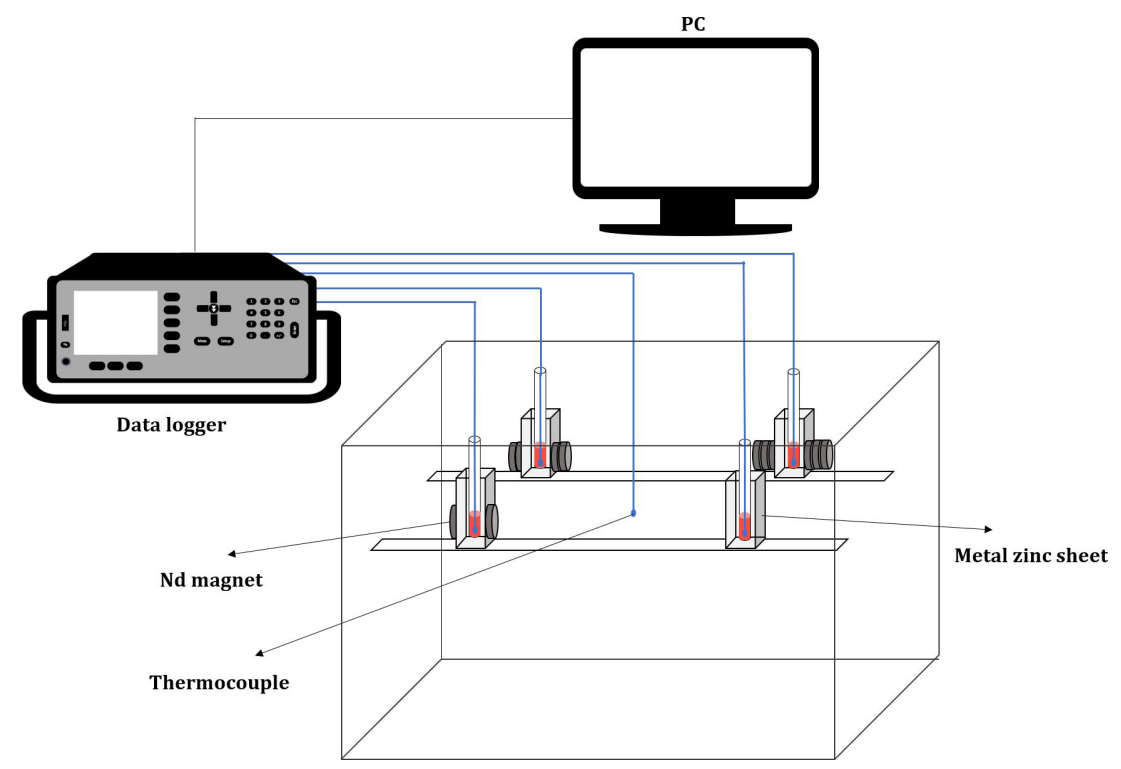

Figure 1. Schematic experiment for freezing of CoNHH in magnetic field. 
can be set to a minimum temperature of approximately $12{ }^{\circ} \mathrm{C}$. The experiment was performed simultaneously for four samples in a test tube, each of them exposed to magnetic fields of different intensities, and a sample without a magnetic field $\left(\mathrm{H}_{0}\right)$ was measured as a reference. Each sample in the test tube was equipped with a temperature sensor positioned at the centre. Three different magnetic field intensities were produced by neodymium magnets with a diameter of $25 \mathrm{~mm}$ and height of $3 \mathrm{~mm}$, which were placed in an attractive arrangement. One, two, and three pairs of magnets were fixed to a metal zinc sheet to produce magnetic field intensities of $\mathrm{H}_{1}=74 \mathrm{mT}, \mathrm{H}_{2}=142 \mathrm{mT}$, and $\mathrm{H}_{3}=215 \mathrm{mT}$, respectively. The nucleation experiment was initiated by immersing the sample in warm water just above the melting point for some minutes to homogenise the temperature inside the sample. When all the samples had melted and reached the same temperature of $60{ }^{\circ} \mathrm{C}$, they were suddenly exposed to a magnetic field and cool temperature environment inside the adiabatic bath, in conjunction with the temperature data recording until all the samples solidified. The experiment was repeated 20 times with a new sample for each measurement, which was used to evaluate each set of parameters due to the complex thermal properties of $\mathrm{CoNHH}$ and the possibility of the phase separation effect, which commonly occurs during the freezing-thawing cycle for salt hydrate $\mathrm{PCMs}^{4-7,10}$.

The statistical analysis of the freezing parameters was performed using the JMP 16 software program with the significance level set at 5\%. The Shapiro-Wilk test was employed to check the normal distribution of the data. If the data fulfilled a normal distribution ( $p$-value $>0.05$ ), a one-way analysis of variance (ANOVA) was performed to determine whether the magnetic field had a significant effect. On the other hand, when the assumption of normality was not fulfilled ( $p$-value $<0.05$ ), the non-parametric Kruskal-Wallis test was employed to compare the characteristic parameters of freezing under different magnetic fields ${ }^{31}$.

Simultaneous thermogravimetric (TG) and differential thermal analyses (DTA) were performed using an STA PT1600 Platinum Series analyser (LINSEIS, USA) under a $\mathrm{N}_{2}$ atmosphere. Samples with amounts in the range 5-15 mg were heated from room temperature to $375^{\circ} \mathrm{C}$ at a constant heating rate of $5 \mathrm{~K} \mathrm{~min}^{-1}$. The data were further analysed to obtain DSC thermograms.
The Fourier transform infrared spectroscopy (FT-IR) spectra of the samples were recorded using an IRPrestige21 (Shimadzu, Japan) spectrometer at 30 scans using the $\mathrm{KBr}$ sampling method.

Hysteresis magnetic measurement was carried out using vibrating sample magnetometry with a maximum applied field of $2 \mathrm{~T}$ to measure the initial sample's magnetisation at room temperature $\left(22^{\circ} \mathrm{C}\right)$.

$\mathrm{X}$-ray diffraction $(\mathrm{XRD})$ patterns of the granular sample were measured at room temperature $\left(22^{\circ} \mathrm{C}\right)$ using a D8 Advance (Bruker) diffractometer, Bragg-Bentano Diffraction and $\mathrm{CuK} \alpha$ radiation $(\lambda=1.54060 \AA)$ for the initial sample of $\mathrm{CoNHH}$ and the CoNHH sample after thawing-freezing in $\mathrm{H}_{2}$. The refinement analysis of the XRD patterns was carried out according to the Rietveld method ${ }^{32}$.

\section{Results and Discussion}

Typical freezing curves of CoNHH at different applied magnetic fields are shown in Figure 2a, while Figure 2b shows the analysis method used to determine the temperature and time characteristics; the effect of the magnetic field on the nucleation of $\mathrm{CoNHH}$ is obvious. The nucleation temperature, $T_{n}$, that occur at nucleation time, $t_{n}$, is the lowest (supercooling temperature) at the first crystal nucleus formation with the critical radius of the crystal, before it increases abruptly due to the release of latent heat to reach a freezing temperature, $T_{f}$, and thereafter, it decreases monotonously. The supercooling degree, $\Delta T_{s}$, is defined as the difference between $T_{f}$ and $T_{n}$. The transition at $T_{n}$ and $T_{f}$ is accompanied by a peak in the time-derivative curve $(d T / d t-t)$. A closer look at the freezing curve shows that two curvatures are evident during the monotonous decrease in temperature after $T_{f}$ owing to the different time-dependent temperature profiles of the latent heat and sensible heat release ${ }^{33}$. Additionally, the border between them is indicated by an inflection in the $d T / d t-t$ curve, with coordinate $\left(t_{i}, T_{i}\right)^{34}$. These time and temperature characteristics limit the growth of crystal dendrites from the nucleus following latent heat release prior to the solid sensible heat release. The crystallisation period $\left(\Delta t_{c}\right)$ is defined as the difference between $t_{i}$ and $t_{n}$.

Prior to the analysis of the magnetic field effect on the freezing behaviour of $\mathrm{CoNHH}$, each temperature and time characteristic data was checked for its normality distribution.
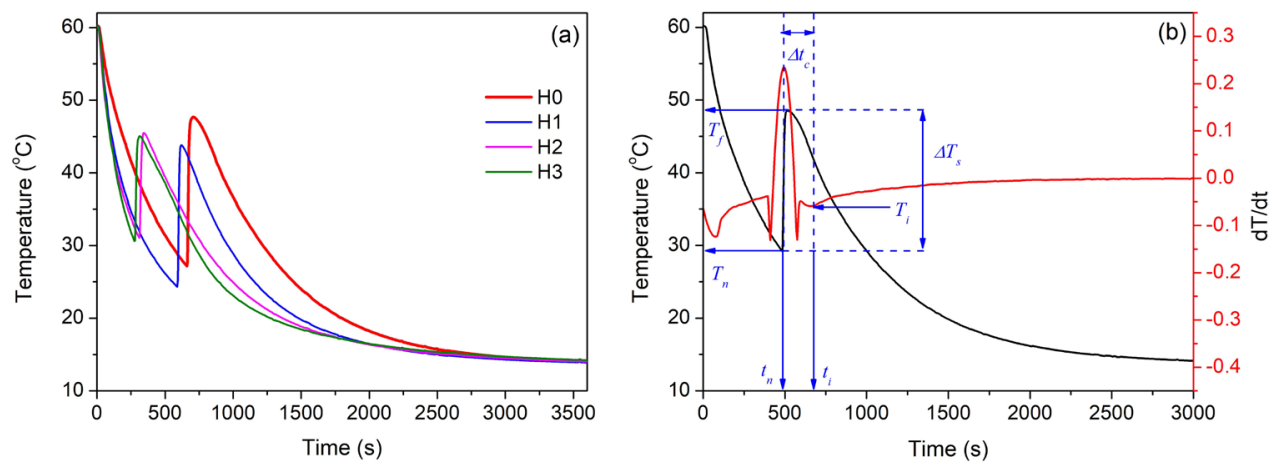

Figure 2. (a) Temperature profile during solidification under different magnetic field intensities. (b) Temperature vs time (black curve) and temperature derivative curve (red line) of CoNHH during solidification. 
The results of the normality test are summarised in Table 2 along with the variance test that shows the corresponding $p$-values. From this table, it may be observed that the magnetic field has a significant effect ( $p$-value $<0.05$ ) on the $t_{n}, T_{f}$ and $t_{f}$, as well as on $T_{i}$ and $t_{i}$. On the other hand, no variance was observed for $T_{n}, \Delta T_{s}$, and $\Delta t_{c}$.

The results of the freezing analysis of $\mathrm{CoNHH}$ under three different applied fields (sample without a field was used as the reference) are shown for the temperature (Figure 3) and time characteristic parameters (Figure 4). Included are the statistical analyses that comprise the means and standard deviation values as well as the quantiles for 20 freeze-thaw cycles.

From Figure 3 one can see that there is no notable trend for $T_{n}, T_{p} T_{i}$ and $\Delta T_{s}$ with changing magnetic field. The result of the variance test shows that the magnetic field effect is clear when the CoNHH sample enters the solid phase. It is worth mentioning that $T_{f}$ was the temperature when a large fraction of the solid phase was formed, and $T_{i}$ indicates the end temperature of the liquid to solid phase change that occurs at $t_{i}$. The significant effect of the magnetic field on the time characteristic parameters of $t_{n}, t_{f}$, and $t_{i}$ is also shown by the decrease of its average values and its smaller variation with the increase in the magnetic field intensity, thus thereby reducing the stochastic behaviour of the nucleation $^{35}$. On the other hand, the supercooling degree and crystallisation period do not show significant variance with change in the magnetic field; that is, it might resemble an extrinsic property of the material, as they affected by the amount of the sample ${ }^{36}$. In the case of supercooling degree, it is also influenced by the cooling rate ${ }^{24,37}$.

We note that the experimental results presented in this study are dissimilar to previous studies for the freezing of

Table 2. $p$-values obtained after applying the Shapiro-Wilk test to check the normality of the data and the Kruskal-Wallis and ANOVA tests to study the significance of the magnetic field on the freezing of CoNHH. Figures in bold indicate the parameter that has a significant effect on the magnetic field.

\begin{tabular}{|c|c|c|c|c|c|c|}
\hline \multirow{2}{*}{$\begin{array}{l}\text { Temperature } \\
\text { parameters }\end{array}$} & \multicolumn{4}{|c|}{ Shapiro-Wilk normality test } & \multirow{2}{*}{ ANOVA } & \multirow{2}{*}{ Kruskal-Wallis } \\
\hline & $\mathrm{H}_{0}$ & $\mathrm{H}_{1}$ & $\mathrm{H}_{2}$ & $\mathrm{H}_{3}$ & & \\
\hline$T_{n}$ & 0.0357 & 0.2659 & 0.0318 & 0.2641 & - & 0.1956 \\
\hline$T_{f}$ & 0.0089 & 0.6779 & 0.0097 & 0.3088 & - & $<0.0001$ \\
\hline$T_{i}$ & 0.0009 & 0.5075 & 0.2892 & 0.0266 & - & $<0.0001$ \\
\hline$\Delta T_{s}$ & 0.0139 & 0.3768 & 0.4938 & 0.7538 & - & 0.3265 \\
\hline \multicolumn{7}{|c|}{ Time parameters } \\
\hline$t_{n}$ & 0.6651 & 0.1249 & 0.2691 & 0.2901 & 0.0012 & - \\
\hline$t_{f}$ & 0.9736 & 0.1259 & 0.2544 & 0.2785 & 0.0003 & - \\
\hline$t_{i}$ & 0.7539 & 0.6419 & 0.9975 & 0.1685 & $<0.0001$ & - \\
\hline$\Delta t_{c}$ & 0.0066 & 0.1165 & 0.3249 & 0.5001 & - & 0.6233 \\
\hline
\end{tabular}
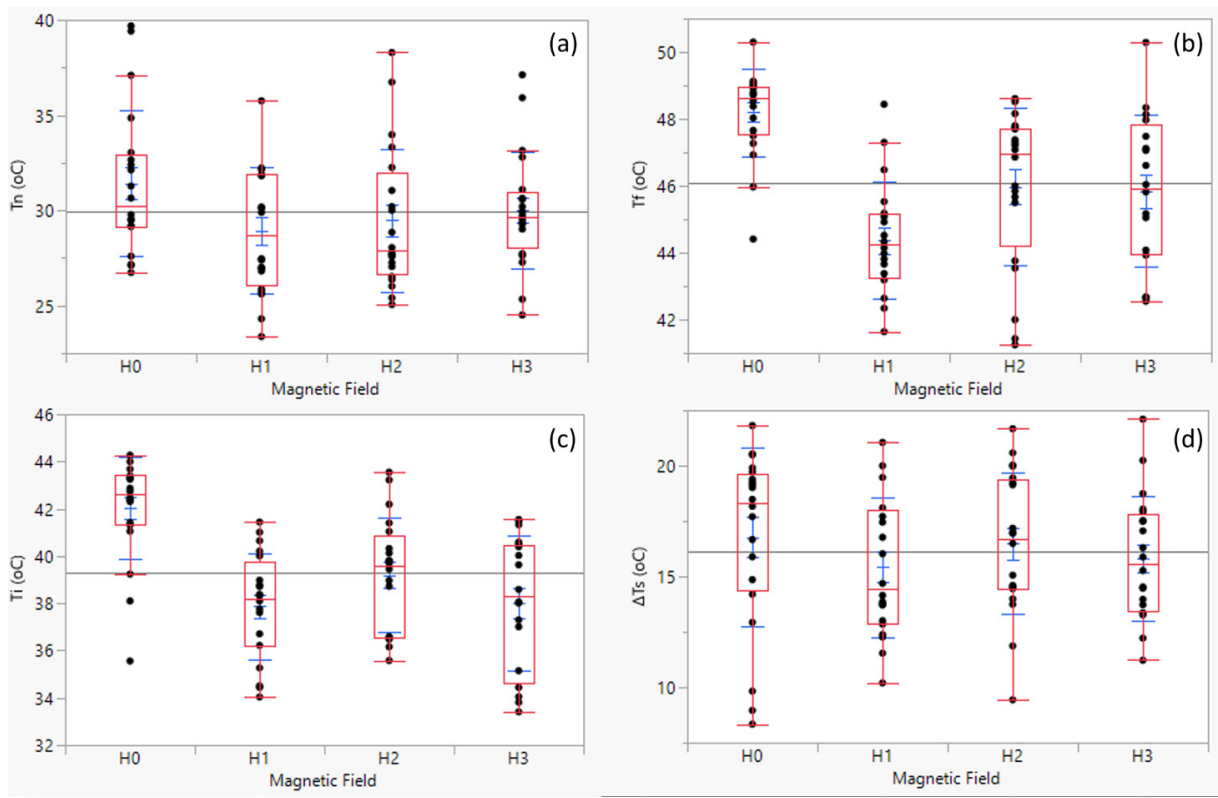

Figure 3. Individual data and statistical analysis of the temperature parameters for freezing of CoNHH as a function of magnetic field intensities: (a) nucleation temperature $\left(T_{n}\right)$, (b) freezing temperature $\left(T_{f}\right)$, (c) inflection temperature $\left(T_{i}\right)$, and (d) supercooling degree $\left(\Delta T_{s}\right)$. 

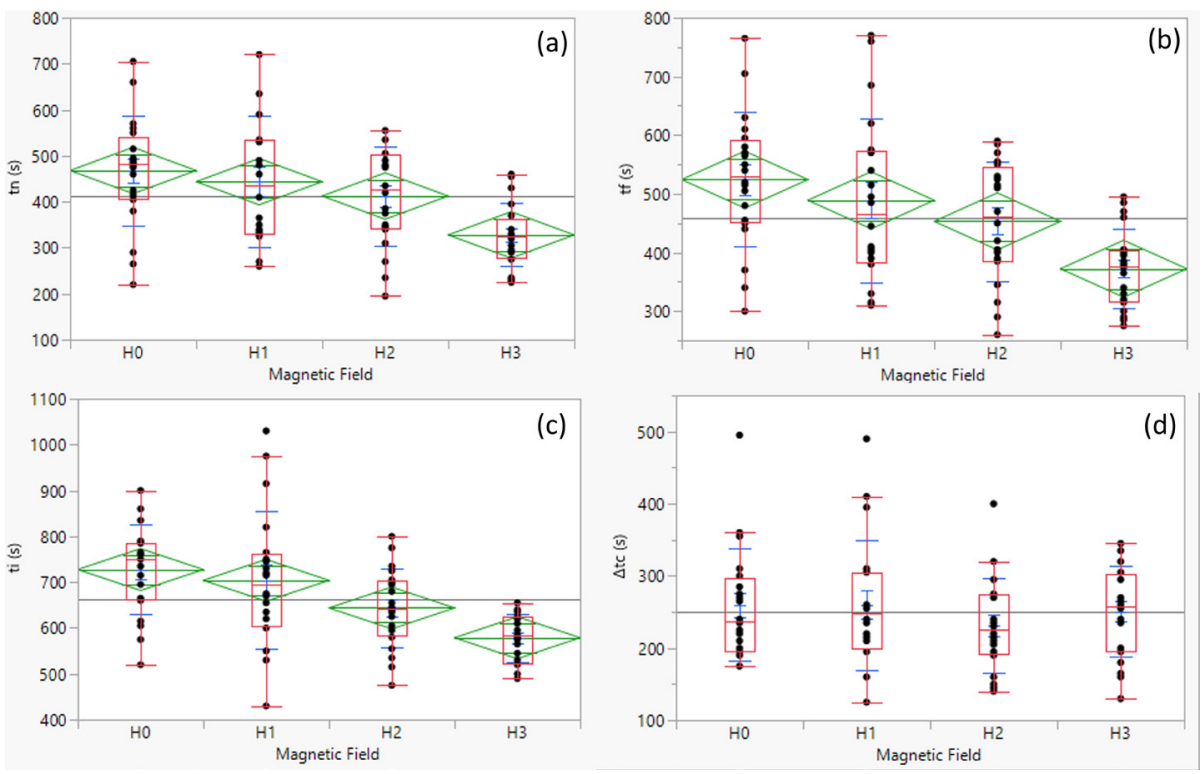

Figure 4. Individual data and statistical analysis of the time parameters for freezing of CoNHH as a function of the magnetic field intensities: (a) nucleation time $\left(t_{n}\right)$, (b) freezing time $\left(t_{f}\right)$, (c) inflection time $\left(t_{i}\right)$, and (d) crystallisation period $\left(\Delta t_{c}\right)$

pure water ${ }^{11,12,15}, 0.9 \% \mathrm{NaCl}$ solutions ${ }^{11,12,18}$, and $5 \%$ ethylene glycol solution ${ }^{12}$. For example, Aleksandrov et al. ${ }^{15}$ reported a continuous decrease in the supercooling degree of a $0.5 \mathrm{~g}$ water sample with a magnetic field of up to $0.5 \mathrm{~T}$ and a negligible change thereafter. Otero et al. ${ }^{11}$ did not find any static magnetic field effect on either the supercooling or freezing kinetics of both $10 \mathrm{~mL}$ pure water samples and $0.9 \% \mathrm{NaCl}$ solutions, although the experiments had been performed intensively for the attractive (107-359 mT) and repulsive poles $(0-241 \mathrm{mT})$. Zhao et al. ${ }^{12}$ showed that although no significant magnetic effect was found for deionised water, clear differences existed for a $0.9 \% \mathrm{NaCl}$ solution and $5 \%$ ethylene glycol solution for a maximum applied field of $43.5 \mathrm{mT}$ ( $5 \mathrm{~mL}$ sample). In particular, the nucleation temperature of the $0.9 \% \mathrm{NaCl}$ decreased in the magnetic field, while its phase transition time was shorter than that in the absence of a magnetic field. On the other hand, the nucleation temperature of 5\% ethylene glycol increased in the magnetic field, while its phase transition time was unaffected by the magnetic field. Mok et al. ${ }^{18}$ showed that ice crystals of $2 \mathrm{~mL}$ of $0.9 \%$ sodium chloride solution treated by the static magnetic field formed irregular shapes with different patterns for both the attractive $(480 \mathrm{mT})$ and repulsive magnetic fields $(50 \mathrm{mT})$, and the phase transition time was highly dependent on the magnetic field configuration.

The thermal properties of CoNHH before and after nucleation experiment are shown in Figure 5, which shows the TGA/DTA and DSC thermograms. The TGA curve of initial sample indicates that $\mathrm{CoNHH}$ decomposes via three weight-loss processes occurring in the temperature ranges of 73-180 ${ }^{\circ} \mathrm{C}, 180-198^{\circ} \mathrm{C}$, and $198-263^{\circ} \mathrm{C}$, in agreement with previous studies ${ }^{24,28}$, particularly for a slow heating rate of $2 \mathrm{~K} \mathrm{~min}^{-1}$ for pronounced phenomena ${ }^{28}$. Moreover, the DTA curve exhibits more than three overlapping endothermic peaks corresponding to the weight-loss phenomena. The results obtained exhibit that dehydration of $\mathrm{CoNHH}$ into tetrahydrate starts at a temperature of approximately $35^{\circ} \mathrm{C}$, which is well below the melting temperature due to incongruent melting ${ }^{29}$. This process mostly occurs at $75^{\circ} \mathrm{C}$ and continuously goes through the dihydrate phase up to $180^{\circ} \mathrm{C}$, with cobalt nitrate monohydrate as an intermediate at $150{ }^{\circ} \mathrm{C}^{28}$ and formation of cobalt (III) oxonitrate (for partial reaction of the water leaving in the third step) ${ }^{29}$. Further heating of the sample to higher temperatures caused thermal decomposition and the formation of anhydrous cobalt nitrate as a major component and cobalt oxides $\left(\mathrm{CoO}, \mathrm{Co}_{2} \mathrm{O}_{3}\right.$, and $\left.\mathrm{Co}_{3} \mathrm{O}_{4}\right)$, instantaneously in an inert atmosphere ${ }^{28,29}$. These intermediate products easily decompose to $\mathrm{Co}_{3} \mathrm{O}_{4}$ as a stable phase ${ }^{28}$. We note that the thermal behaviour of CoNHH depends sensitively on the experimental conditions at a particular heating rate, as rapid heating causes a hydrate melt which changes the system drastically with side reactions and evaporation of $\mathrm{HNO}_{3}$ and other species, resulting in a more contour-less TG curve ${ }^{28}$. From DSC thermogram, the melting temperature is $56^{\circ} \mathrm{C}$, and this result is in good agreement with previous studies (Table 1).

Thawing-freezing in magnetic fields gives rise to some changes in the TG and DTA curves. A shift to a lower temperature for the onset of the TG curve signifies the beginning of the decomposition followed by a more step transition. Overlapping DTA peaks at a temperature just above the first decomposition step above $75^{\circ} \mathrm{C}$ followed by a new DTA signal at a high temperature between $200-263^{\circ} \mathrm{C}$. The DSC thermogram also indicates the decrease of the melting temperature and melting enthalpy. However, indirect measurement has a hindering effect on the accuracy of melting enthalpy from the DSC data.

The FT-IR spectra shown in Figure 6 show broad peaks at approximately $3640 \mathrm{~cm}^{-1}$ and $1687 \mathrm{~cm}^{-1}$ due to $\mathrm{OH}$ stretching and bending of water $\left(\mathrm{H}_{2} \mathrm{O}\right)^{38}$, which are indicative of an ionic unperturbed nitrate ${ }^{39}$. The spectra show some characteristic bands due to nitrate ions $\left(\mathrm{NO}_{3}^{-}\right)$, 

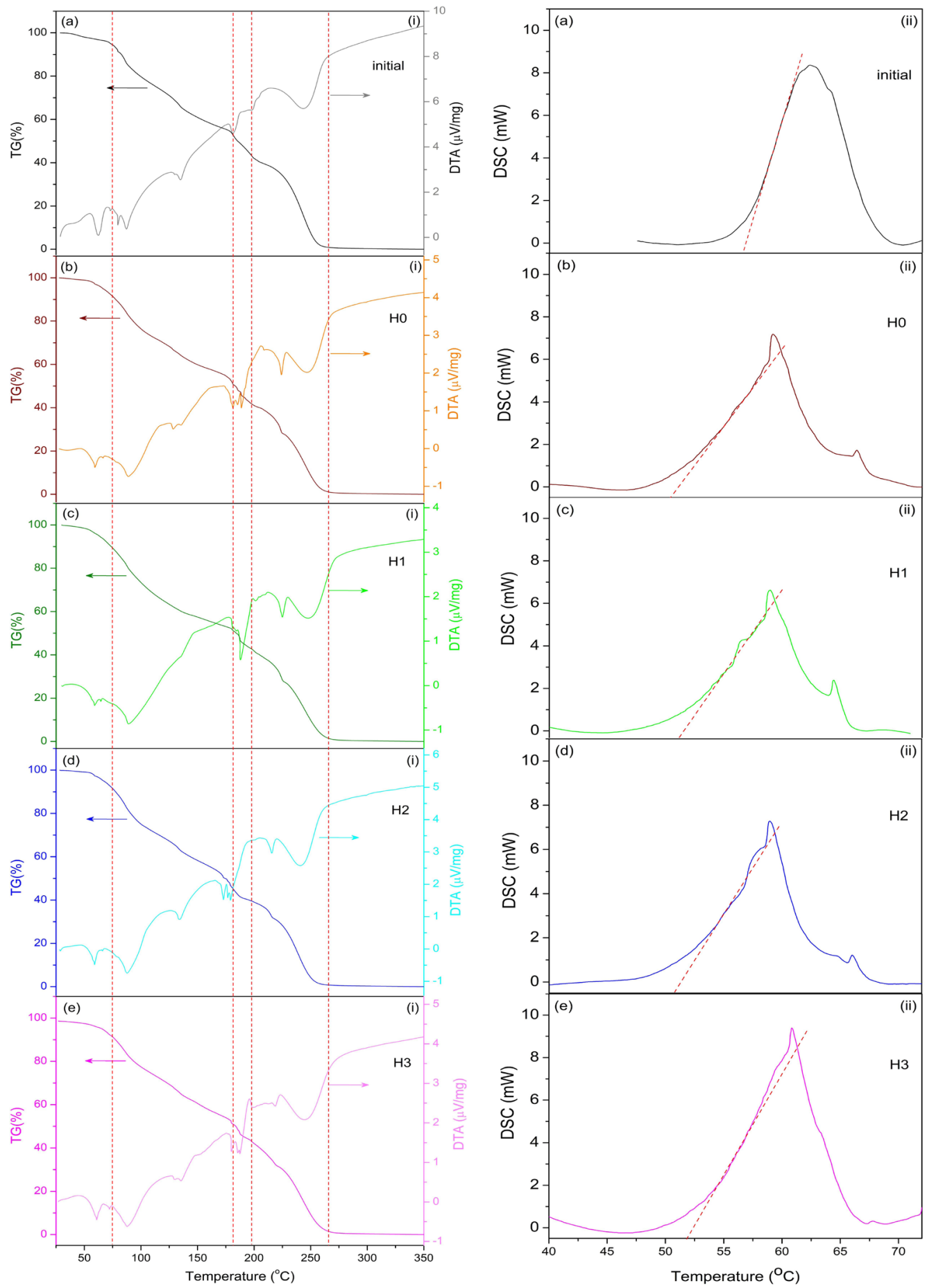

Figure 5. Left: TGA/DTA curves, and right: DSC thermogram, of (a) initial sample of CoNHH, and (b)-(e) CoNHH after thawing-freezing in different magnetic fields of: $\mathrm{H}_{0}, \mathrm{H}_{1}, \mathrm{H}_{2}$, and $\mathrm{H}_{3}$.

in addition to Co-N vibration at $1172 \mathrm{~cm}^{-1} 28$. Moreover, the characteristic bands for anhydrous cobalt nitrate ${ }^{29,39,40}$, dihydrate, and hexahydrate ${ }^{29,39}$ were also observed with relatively small intensity.

FT-IR spectroscopy performed after the nucleation experiment showed prominent changes in the fingerprint region (500-1500 $\left.\mathrm{cm}^{-1}\right)$. In general, the peak's position due to $\mathrm{H}_{2} \mathrm{O}$ did not change, but its intensity increased after the freezing-thawing cycle in the different magnetic fields, namely, $\mathrm{H}_{0}, \mathrm{H}_{1}, \mathrm{H}_{2}$, and $\mathrm{H}_{3}$. This result signified the possibility of a phase separation effect. On the other hand, the peak intensity due to the formation of cobalt nitrate 


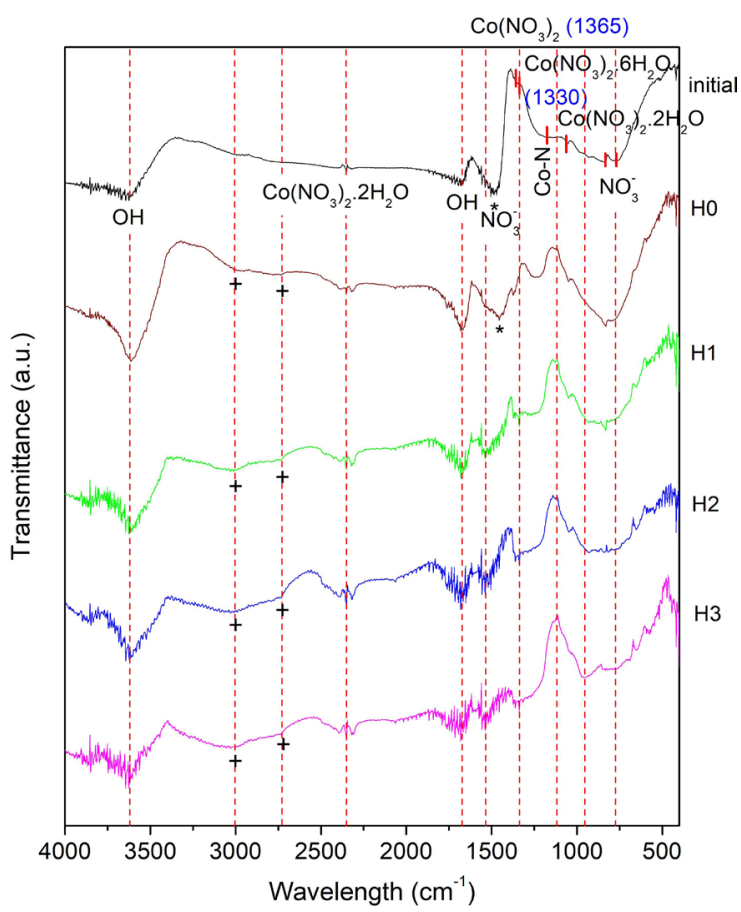

Figure 6. FT-IR spectra of CoNHH in the range of $400-4000 \mathrm{~cm}^{-1}$ for the initial sample, and for the samples after thawing-freezing in different magnetic fields of: $\mathrm{H}_{0}, \mathrm{H}_{1}, \mathrm{H}_{2}$, and $\mathrm{H}_{3}$. dihydrate at approximately $2355 \mathrm{~cm}^{-1}$ increased. Crucially, the peaks due to the nitrate ions shifted significantly from $1485 \mathrm{~cm}^{-1}$ for the initial sample to $1454 \mathrm{~cm}^{-1}$ for $\mathrm{H}_{0}$ (marked with an asterisk in Figure 6). These peaks disappeared for the samples that experienced freezing at different magnetic field intensities, with the simultaneous appearance of a new peak at approximately $1530 \mathrm{~cm}^{-1}$. Similar phenomena occurred for the peaks at $830 \mathrm{~cm}^{-1}$ and might be due to the evaporation of nitrate ions from the sample. The emergence of a broad peak at approximately $3000 \mathrm{~cm}^{-1}$ and a weak shoulder at approximately $2700 \mathrm{~cm}^{-1}$ while freezing the CoNHH in the absence and in the presence of a magnetic field conditions (cross in Figure 6) that became more pronounced with the increase in magnetic field intensity was presumably due to the formation of cobalt nitrate with a lower hydrate number.

Figure 7 shows the results of the structural analysis of CoNHH that displays the refinement of the XRD spectrum of the initial sample and the CoNHH sample after thawingfreezing in $\mathrm{H}_{2}$. Both samples show the pure phase of $\mathrm{CoNHH}$ without any sign of the impurity phases. The results of the XRD refinement are summarised in Table 3, which shows the lattice parameters of $\mathrm{CoNHH}$ in comparison to a previous study ${ }^{22}$.

It is tempting at this point to correlate the freezing behaviour of CoNHH in a static magnetic field to its magnetisation and compare it with previous studies for the nucleation of water

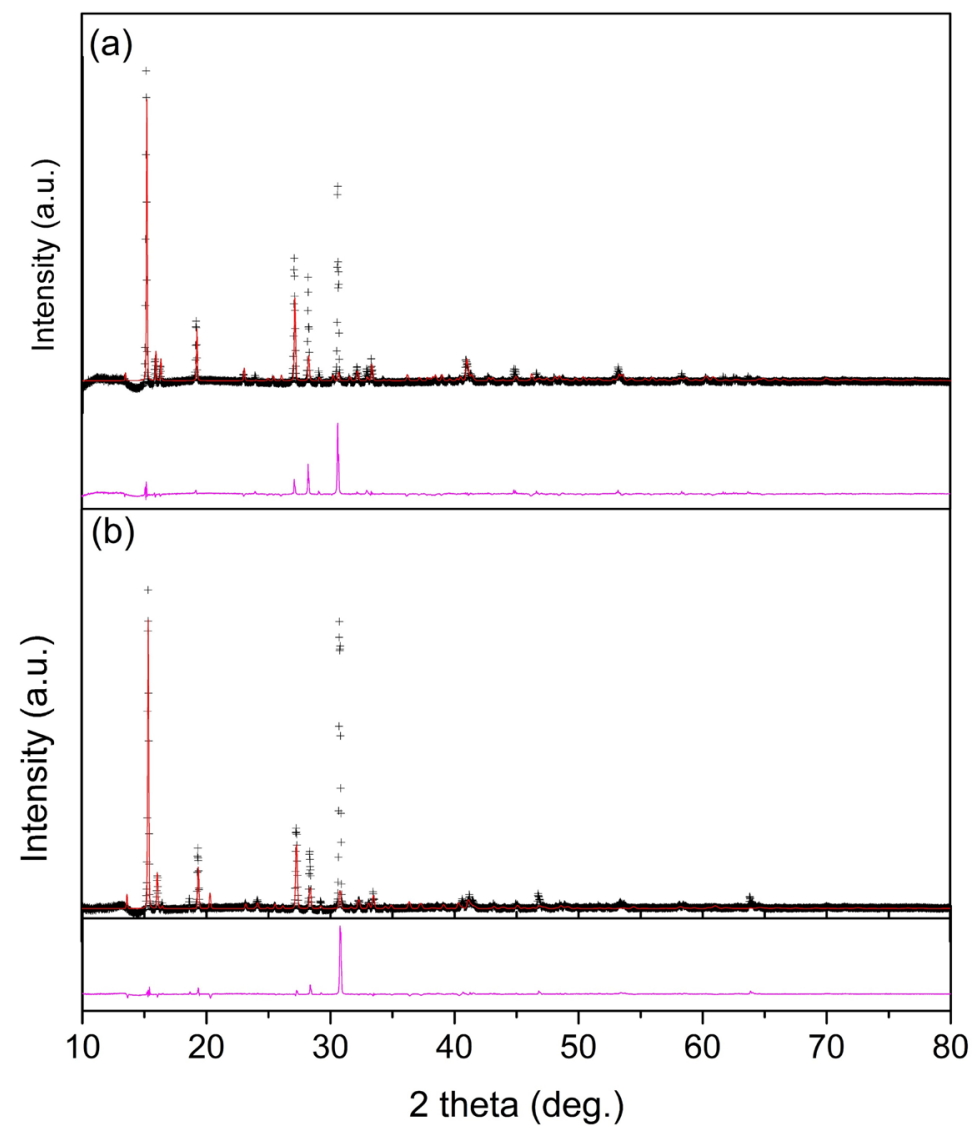

Figure 7. XRD patterns of (a) initial sample of $\mathrm{CoNHH}$ and (b) $\mathrm{CoNHH}$ after thawing-freezing in a magnetic field of $\mathrm{H}_{2}$ presented as the observed (crosses) and calculated (full lines) results as well as their differences (bottom trace). 
Table 3. Lattice parameters of initial sample of CoNHH and CoNHH after thawing-freezing in a magnetic field of $\mathrm{H}_{2}$, and the corresponding data from reference ${ }^{22}$.

\begin{tabular}{ccc}
\hline \multicolumn{2}{c}{ SoNHH } & $\begin{array}{c}\text { CoNHH after } \\
\text { thawing-freezing in a } \\
\text { magnetic field of } \mathrm{H}_{2}\end{array}$ \\
\hline $\begin{array}{c}\text { Initial sample } \\
\text { (present work) }\end{array}$ & Prelesnik et al. ${ }^{22}$ & $a=14.94 \AA$ \\
\hline$a=14.96 \AA$ & $a=14.96 \AA$ & $b=6.135 \AA$ \\
\hline$b=6.136 \AA$ & $b=6.112 \AA$ & $c=12.659 \AA$ \\
\hline$c=12.662 \AA$ & $c=12.632 \AA$ & $\beta=118.44^{\circ}$ \\
\hline$\beta=118.44^{\circ}$ & $\beta=118.45^{\circ}$ & \\
\hline
\end{tabular}

or salt solution. In this case, the magnetisation $M$ is related to the material's response to the applied magnetic field $H^{41}$.

$$
M=\chi H
$$

where $\chi$ is the magnetic susceptibility. In contrast to the diamagnetic response of water ${ }^{42}$, the $M-H$ curve taken at room temperature $\left(T=22^{\circ} \mathrm{C}\right)$, as seen in Figure 8, shows that $\mathrm{CoNHH}$ is weakly ferromagnetic. The hysteresis behaviour is clearly seen at applied fields below $500 \mathrm{mT}$, and the coercive field is approximately $40 \mathrm{mT}$.

It has been experimentally demonstrated that the static magnetic field changes the structure and physicochemical properties of water ${ }^{43}$. In particular, water becomes more stable by magnetic treatment with less molecular energy and more activation energy, thus indicating that the average size of water clusters becomes larger with magnetic treatments, resulting in the formation of more hydrogen bonds and enhancement of its strength ${ }^{13,43}$. This is in agreement with the results of an intensive simulation study that predicted that the structure of the water is more stable and the ability of the water molecules to form hydrogen bonds is enhanced when a magnetic field is applied ${ }^{44}$. In other words, the magnetic field constrains the movement of the water molecules, thus inhibiting the vibration and rotation of molecules to promote nucleation at higher freezing temperatures with the enhancement of the magnetic field ${ }^{45}$. We note that in the case of water, the breakup of the hydrogen bond leads to an increase in diamagnetism ${ }^{46-48}$. In the case of an aqueous $\mathrm{NaCl}$ electrolyte solution, the effect of the magnetic field on hydrogen bonding very sensitively depends on the concentration of the solution. In a low-concentration solution, the structural behaviour is dominated by the properties of the water molecules, and hence the hydrogen bonding ability is enhanced as the magnetic field is increased, just as in the case of pure water. Conversely, the enhanced mobility of the ions under a magnetic field causes serious damage to the hydrogen bond network in a high-concentration solution ${ }^{49}$.

Application of an external electric field and a magnetic field is expected to exert opposite effects on the number of hydrogen bonds, that is, an electric field breaks the hydrogen bond network, while a magnetic field enhances the hydrogen bonding ${ }^{44}$. However, for an appropriate condition, the thermodynamic formulation might be presumed similar, as both methods have resulted in a smaller crystal size ${ }^{8,9}$.

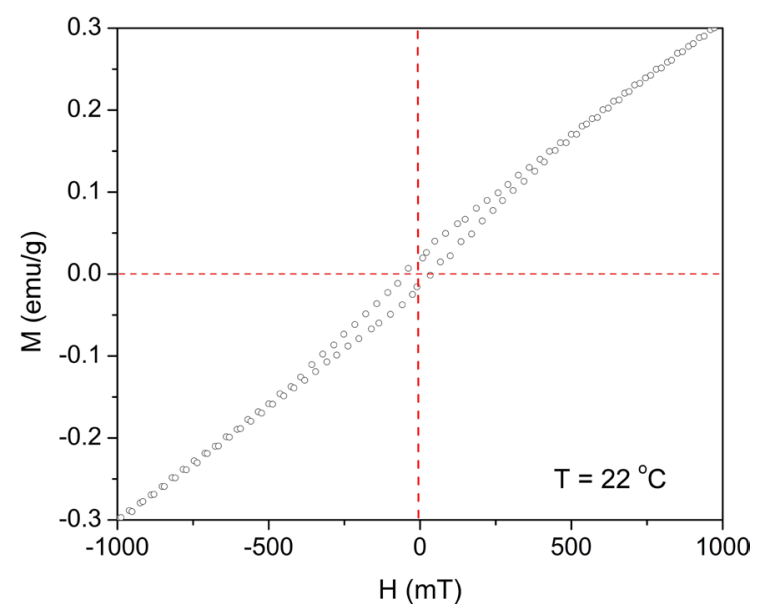

Figure 8. Magnetisation curve of $\mathrm{CoNHH}$ at $22^{\circ} \mathrm{C}$.

The energy due to the magnetic field is presumed to be much lower than the electrical or mechanical energy and highly depends on the sample's amount. Hence, we propose that the effect of the application of a magnetic field on nucleation can be described by the change in the Gibbs free-energy $(\Delta G)$ of the system. A new $M H$ term might be added to the volume contribution of $\Delta G^{50,51}$,

$$
\Delta G_{H}=\Delta G_{0}+M H
$$

where $M$ is the magnetisation, $H$ is the intensity of the magnetic field, and $\Delta G_{0}$ is the Gibbs free-energy in the absence of magnetic field. Thus, the effect of the magnetic field on the nucleation of water and water-based materials is dependent very sensitively on the hydrogen bonding, in addition to magnetisation and temperature, as an increase in temperature generally leads to the randomising effect of thermal agitation. The appropriate mechanism for water and CoNHH might be different, as the increase in temperature might hamper the ferromagnetic ordering of CoNHH.

\section{Conclusions}

The nucleation of magnetic PCM CoNHH at different static magnetic fields shows that the magnetic field has a significant effect on the nucleation time, freezing time and temperature, and inflection time and temperature. In this case, the decrease in average values of $t_{n}, t_{f}$, and $t_{i}$ with the increase in the magnetic field intensity is accompanied by a smaller variation for the 20 freeze-thaw cycles data. On the other hand, the results also reveal no magnetic field effect on the supercooling degree and crystallisation period. The thermal properties of $\mathrm{CoNHH}$ reveal the stepwise formation of distinct hydrates, including hexa-, tetra- and di-hydrate of cobalt nitrate, anhydrous cobalt(II)nitrate, as well as cobalt oxides. The melting temperature from the DSC thermogram is $56^{\circ} \mathrm{C}$. Thawing-freezing in magnetic fields gives rise to changes in the TG and DTA curves, namely a shift to a lower decomposition temperature and overlapping and the growth of new DTA peaks. The DSC thermogram 
also indicates the decrease of the melting temperature and melting enthalpy. FT-IR spectra show the characteristic band structures of $\mathrm{H}_{2} \mathrm{O}$, nitrate ion, and $\mathrm{Co}-\mathrm{N}$ vibrations, in addition to anhydrous, dihydrate, hexahydrate, and cobalt nitrate. FTIR spectra showed significant change for the sample after the freeze-thaw cycle at zero or in a magnetic field. This result signifies the occurrence of cobalt nitrate with a lower hydrate number, phase separation effect, and evaporation of $\mathrm{NO}_{3}{ }^{-}$ions. The result of the XRD refinement data of the initial sample revealed the lattice parameters, which closely resembled those of the reference. The freezing-thawing in a magnetic field gives the effect to the slight lattice parameter change. The magnetisation measured at room temperature $\left(22^{\circ} \mathrm{C}\right)$ showed that $\mathrm{CoNHH}$ is a weak ferromagnetic with hysteresis behaviour below $500 \mathrm{mT}$ and the coercive field is approximately $40 \mathrm{mT}$. The results were compared with previous studies for the nucleation of water, a salt solution, and an ethylene glycol solution, and discussed in terms of hydrogen bonding and the measured magnetic properties. The observed magnetic field effect of CoNHH nucleation when the sample enters the solid phase might be related to the alignment of the magnetic moments of cobalt ions in the periodic structure of the solid phase. Due to the relatively small energy of the magnetic field, its effect on nucleation might be highly dependent on the sample quantity and the material's magnetic properties, in addition to its interplay with hydrogen bonding.

The results of this study might provide an understanding of the static magnetic field effect on the nucleation of materials. Minimising the phase separation effect with a suitable nucleator agent or thickening agent is an important task to optimise the performance of $\mathrm{CoNHH}$ as latent TES. A challenge is to expand this experimental study using a pulsed or oscillating magnetic field with varying frequencies to fully understand the mechanism behind it. It would also be interesting to study the importance of the magnetic field effect for the nucleation of any PCM using an additional nanoparticle magnetic dopant with various types and concentrations in response to the applied magnetic field.

\section{Acknowledgements}

We would like to thank Dr. Surjani Wonorahardjo (Universitas Negeri Malang) for FT-IR measurements, PPNN ITB for simultaneous TG-DTA/DSC measurements, Batan Indonesia for magnetization measurements, and LIPI Indonesia for XRD measurement.

This work was financially supported by the Desentralisasi 2020 research program from Kementrian Riset dan Teknologi/ Badan Riset dan Inovasi Nasional of the Indonesian government under Grant number 2/E1/KP.PTNBH/2020.

We would like to thank Editage (www.editage.com) for the English language editing.

\section{References}

1. Sarbu I, Sebarchievici C. A comprehensive review of thermal energy storage. Sustain. 2018;10(1):191. http://dx.doi.org/10.3390/ su10010191.

2. Dinçer İ, Rosen MA. Thermal energy storage system and applications. 2nd ed. USA: John Wiley \& Sons; 2011.
3. Bruno F, Belusko M, Liu M, Tay NHS. Using solid-liquid phase change materials (PCMs) in thermal energy storage systems. In: Cabeza LF, editor. Advances in thermal energy storage systems, methods and applications. Cambridge: Woodhead; 2015. p. 201-46.

4. Fleischer AS. Thermal energy storage using phase change materials: fundamentals and applications. Villanova: Springer; 2015. Springer Briefs in Applied Sciences and Technology. http://dx.doi.org/10.1007/978-3-319-20922-7.

5. Rostami S, Afrand M, Shahsavar A, Sheikholeslami M, Kalbasi $\mathrm{R}$, Aghakhani S, et al. A review of melting and freezing processes of PCM/nano-PCM and their application in energy storage. Energy. 2020;211:118698. http://dx.doi.org/10.1016/j. energy.2020.118698.

6. Kenisarin M, Mahkamov K. Salt hydrates as latent heat storage materials: thermophysical properties and costs. Sol Energy Mater Sol Cells. 2016;145:255-86. http://dx.doi.org/10.1016/j. solmat.2015.10.029.

7. Purohit BK, Sistla VS. Inorganic salt hydrate for thermal energy storage application: a review. J Energy Storage. 2020;3(2):e212. http://dx.doi.org/10.1002/est2.212.

8. Dalvi-isfahan M, Hamdami N, Xanthakis E, Le-bail A. Review on the control of ice nucleation by ultrasound waves, electric and magnetic fields. J Food Eng. 2017;195:222-34. http:// dx.doi.org/10.1016/j.jfoodeng.2016.10.001.

9. Jha PK, Xanthakis E, Jury V, Le-bail A. An overview on magnetic field and electric field interactions with ice crystallisation; application in the Case of Frozen Food. Crystals. 2017;7(10):299. http://dx.doi.org/10.3390/cryst7100299.

10. Beaupere N, Soupremanien U, Zalewski L. Nucleation triggering methods in supercooled phase change materials (PCM), a review. Thermochim Acta. 2018;670:184-201. http://dx.doi. org/10.1016/j.tca.2018.10.009.

11. Otero L, Rodríguez AC, Sanz PD. Effects of static magnetic fields on supercooling and freezing kinetics of pure water and 0.9\% NaCl solutions. J Food Eng. 2018;217:34-42. http:// dx.doi.org/10.1016/j.jfoodeng.2017.08.007.

12. Zhao H, Zhang F, Hu H, Liu S, Han J. Experimental study on freezing of liquids under static magnetic field. Chin J Chem Eng. 2017;25(9):1288-93. http://dx.doi.org/10.1016/j. cjche.2016.10.026.

13. Inaba H, Saitou T, Tozaki KI, Hayashi H. Effect of the magnetic field on the melting transition of $\mathrm{H}_{2} \mathrm{O}$ and $\mathrm{D}_{2} \mathrm{O}$ measured by a high resolution and supersensitive differential scanning calorimeter. J Appl Phys. 2004;96(11):6127-32. http://dx.doi. org/10.1063/1.1803922.

14. Woo MW, Mujumdar AS. Effects of electric and magnetic field on freezing and possible relevance in freeze drying. Dry Technol. 2010;28(4):433-43. http://dx.doi.org/10.1080/07373930903202077.

15. Aleksandrov VD, Barannikov AA, Dobritsa NV. Effect of magnetic field on the supercooling of water drops. Inorg Mater. 2000;36(9):895-8. http://dx.doi.org/10.1007/BF02758700.

16. Otero L, Rodríguez AC, Pérez-Mateos M, Sanz PD. Effects of magnetic fields on freezing: application to biological products. Compr Rev Food Sci Food Saf. 2016;15:646-67. http://dx.doi. org/10.1111/1541-4337.12202.

17. Otero L, Pérez-mateos M, RodríguezAC, Sanz PD. Electromagnetic freezing: effects of weak oscillating magnetic fields on crab sticks. J Food Eng. 2017;200:87-94. http://dx.doi.org/10.1016/j. jfoodeng.2016.12.018.

18. Mok JH, Choi W, Park SH, Lee SH, Jun S. Emerging pulsed electric field (PEF) and static magnetic field (SMF) combination technology for food freezing. Int J Refrig. 2015;50:137-45. http://dx.doi.org/10.1016/j.ijrefrig.2014.10.025.

19. Kang T, You Y, Jun S. Supercooling preservation technology in food and biological samples: a review focused on electric and magnetic field applications. Food Sci Biotechnol. 2020;29(3):30321. http://dx.doi.org/10.1007/s10068-020-00750-6. 
20. CAS Technology Revolutionizes Preservation. An ideal for freezing food [Internet]. 2021 [cited 2021 Feb 16]. Available from: https:/www.japan.go.jp/_src/277418/autumnwinter15_30-31. pdf

21. Proton Europe. Proton magnetic freezer [Internet]. 2021 [cited $2021 \mathrm{Feb}$ 16]. Available from: https://static.showit.co/file/ HtKHBMubRfm8c0UF52K42Q/96831/1pdf_proton_tech_2020. pdf

22. Prelesnik PV, Gabela F, Ribar B, Krstanovic I. Hexaaquacobalt(II) nitrate. Cryst Struct Commun. 1973;2:581-3.

23. Jayaraman A. Unit cell parameters, space-group and optical properties of cobalt nitrate hexahydrate. Proc Indian Acad Sci Sect A Phys Sci. 1958;47(3):147-9. http://dx.doi.org/10.1007/ BF03052633.

24. Honcová P, Sádovská G, Binder L, Koštál P, Honc D. Calorimetric examination of suitability of calcium, cobalt and nickel nitrate hydrates for thermal energy storage. J Therm Anal Calorim. 2020;142:275-87. http://dx.doi.org/10.1007/ s10973-020-09435-y.

25. Silalahi AO, Sutjahja IM, Kurnia D, Wonorahardjo S. The enthalpy-temperature curve of new $\mathrm{PCM} \mathrm{Ca}\left(\mathrm{NO}_{3}\right)_{2} \cdot 4 \mathrm{H}_{2} \mathrm{O}$ and $\mathrm{Co}\left(\mathrm{NO}_{3}\right)_{2} \cdot 6 \mathrm{H}_{2} \mathrm{O}$ for low-temperature latent TES. J Phys Conf Ser. 2019;1204:012057. http://dx.doi.org/10.1088/1742$6596 / 1204 / 1 / 012057$

26. Marcus Y, Minevich A, Ben-Dor L. Solid-liquid equilibrium diagrams of common ion binary salt hydrate mixtures involving nitrates and chlorides of magnesium, cobalt, nickel, manganese, and iron(III). Thermochim Acta. 2005;432(1):23-9. http://dx.doi. org/10.1016/j.tca.2005.04.003.

27. Guion J, Sauzade JD, Laügt M. Critical examination and experimental determination of melting enthalpies and entropies of salt hydrates. Thermochim Acta. 1983;67(2-3):167-79. http:// dx.doi.org/10.1016/0040-6031(83)80096-3.

28. Mansour SAA. Spectrothermal studies on the decomposition course of cobalt oxysalts Part III. Cobalt oxalate dihydrate. Mater Chem Phys. 1994;36(3-4):324-31. http://dx.doi. org/10.1016/0254-0584(94)90049-3.

29. Ehrhardt C, Gjikaj M, Brockner W. Thermal decomposition of cobalt nitrato compounds: preparation of anhydrous cobalt(II) nitrate and its characterisation by Infrared and Raman spectra. Thermochim Acta. 2005;432(1):36-40. http://dx.doi.org/10.1016/j. tca.2005.04.010.

30. Applent Instruments Inc. Applent Instrument AT4508A Multichannel Temperature Meter: User's Guide. Jiangsu Province, China: Applent Instruments Inc.; 2009.

31. Upton G, Cook I. Dictionary of Statistic. USA: Oxford University Press; 2002.

32. Larson AC, Von Dreele RB. General Structure Analysis System (GSAS). New Mexico: Los Alamos National Laboratory; 1994. Los Alamos National Laboratory Report, LAUR 86-748.

33. Hong H, Kim SK, Kim Y. Accuracy improvement of T-history method for measuring heat of fusion of various materials. Int J Refrig. 2004;27(4):360-6. http://dx.doi.org/10.1016/j. ijrefrig.2003.12.006.
34. Sutjahja IM, Silalahi A, Kurnia D, Wonorahardjo S. Thermophysical parameters and enthalpy-temperature curve of phase change material with supercooling from T-history data. UPB Sci Bull Series B. 2018;80(2):57-70.

35. Myerson AS. Concluding remarks. Faraday Discuss. 2015;179:5437. http://dx.doi.org/10.1039/C5FD00042D.

36. Mehling H, Cabeza LF. Heat and cold storage with PCM, an up to date introduction into basics and applications. Berlin, Germany: Springer; 2008.

37. Safari A, Saidur R, Sulaiman FA, Xu Y, Dong J. A review on supercooling of Phase Change Materials in thermal energy storage systems. Renew Sustain Energy Rev. 2017;70:905-19. http://dx.doi.org/10.1016/j.rser.2016.11.272.

38. Falk M, Ford TA. Infrared spectrum and structure of liquid water. Can J Chem. 1966;44(14):1699-707. http://dx.doi.org/10.1139/ v66-255.

39. Ferraro JR, Walker A. Comparison of the infrared spectra (4000-70 $\mathrm{cm}^{-1}$ ) of several hydrated and anhydrous salts of transition metals. J Chem Phys. 1965;42(4):1278-85. http:// dx.doi.org/10.1063/1.1696110.

40. Addison CC, Gatehouse BM. The infrared spectra of anhydrous transition-metal nitrates. J Chem Soc. 1960;1:613-6. http:// dx.doi.org/10.1039/JR9600000613.

41. Cullity BD, Graham CD. Introduction to magnetic materials. Hoboken: John Wiley \& Sons; 2009.

42. Philo JS, Fairbank WM. Temperature dependence of the diamagnetism of water. J Chem Phys. 1980;72(8):4429-33. http://dx.doi.org/10.1063/1.439734.

43. Cai R, Yang H, He J, Zhu W. The effects of magnetic fields on water molecular hydrogen bonds. J Mol Struct. 2009;938(13):15-9. http://dx.doi.org/10.1016/j.molstruc.2009.08.037.

44. Chang KT, Weng CI. The effect of an external magnetic field on the structure of liquid water using molecular dynamics simulation. J Appl Phys. 2006;100:043917. http://dx.doi. org/10.1063/1.2335971.

45. Zhang G, Zhang W, Dong H. Magnetic freezing of confined water. J Chem Phys. 2010;133:134703. http://dx.doi. org/10.1063/1.3498747.

46. Angus WR, Hill WK. Diamagnetism and the hydrogen bond. Trans Faraday Soc. 1940;36:923-7. http://dx.doi.org/10.1039/ TF9403600923.

47. Anantakrishnan SV, Varadachari PS. The hydrogen bond and diamagnetism. Proc Indian Acad Sci Sect A Phys Sci. 1944;20(3):128-37. http://dx.doi.org/10.1007/BF03046861.

48. Cini R, Torhini M. Temperature dependence of the magnetic susceptibility of water. J Chem Phys. 1968;49(6):2826-30. http://dx.doi.org/10.1063/1.1670491.

49. Chang KT, Weng CI. An investigation into the structure of aqueous $\mathrm{NaCl}$ electrolyte solutions under magnetic fields. Comput Mater Sci. 2008;43(4):1048-55. http://dx.doi.org/10.1016/j. commatsci.2008.02.020.

50. Chalmers B. Principles of solidification. New York: Wiley; 1964.

51. Mullin JW. Crystallization. 4th ed. Woburn, MA: Reed Educational and Professional Publishing Ltd; 2001. 